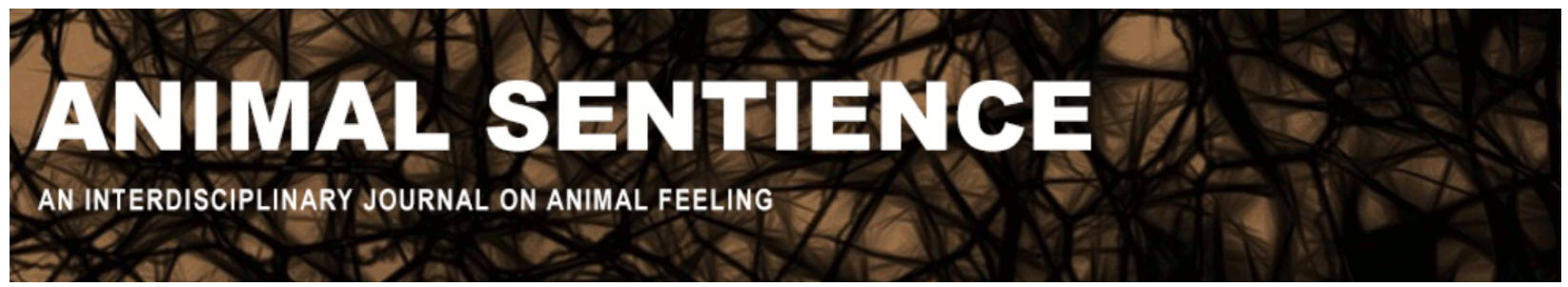

Palmer, Clare and Sandøe, Peter (2019) Yes, sheep are smart but the moral question is still "can they suffer?". Animal Sentience 25(24)

DOI: $10.51291 / 2377-7478.1463$

Date of submission: 2019-05-27

Date of acceptance: 2019-06-04 (c)

This article has appeared in the journal Animal Sentience, a peer-reviewed journal on animal cognition and feeling. It has been made open access, free for all, by WellBeing International and deposited in the WBI Studies Repository. For more information, please contact

wbisr-info@wellbeingintl.org.

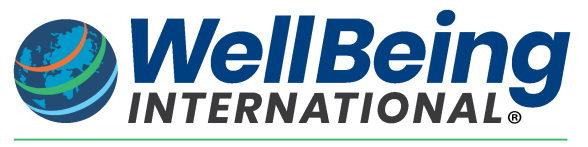

SOLUTIONS FOR PEOPLE, ANIMALS AND ENVIRONMENT 


\title{
Yes, sheep are smart but the moral question is still "can they suffer?"
}

Commentary on Marino \& Merskin on Sheep Complexity

\author{
Clare Palmer \\ Texas A\&M University \\ Peter Sandøe \\ University of Copenhagen
}

\begin{abstract}
Sheep may be more complex and intelligent than we traditionally believed, but knowing this is unlikely to change human attitudes to sheep significantly; nor is it strongly relevant to their moral status. However, knowing more about what sheep are like could help to improve sheep welfare.
\end{abstract}

Clare Palmer is Professor of Philosophy at Texas
A\&M University. Her research interests are in
animal ethics, environmental ethics, and the
ethics of emerging technologies. Website

Peter Sandøe, originally trained as a philosopher at the University of Copenhagen and at Oxford University, is currently professor of bioethics at the University of Copenhagen. Website
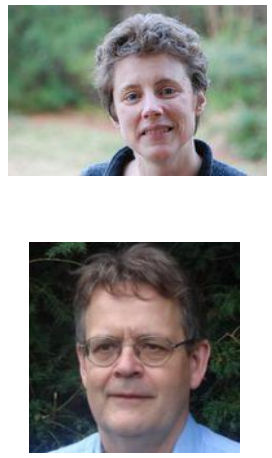

Marino \& Merskin (2019) (M\&M) maintain that humans have traditionally thought of sheep as docile and stupid. Their target article argues that these views are not based on good evidence; and they draw on a range of scientific studies to support their claim that sheep are more complex and intelligent than has been previously recognized. M\&M then conclude:

"It is our hope that this comprehensive analysis of scientific literature will serve as the foundation for reconsidering the use of sheep as commodities in modern agricultural production and in invasive research ..."

So, a central hope of their paper is that bringing evidence of sheep intelligence to light might lead to changes in the way sheep are treated. It is unclear, however, on what the authors are basing this hope. Is it a hope about human psychology, that if people understand how smart sheep really are, they will change their attitudes and treat them better? Or is it a normative claim, to the effect that if animals (in this case sheep) are smart, there is a stronger ethical obligation to treat them well than if they are stupid?

In psychological terms, however, it is unclear whether evidence that a species of animal is smarter than has been previously thought is likely to change human attitudes and practices concerning them. Human psychological reactions to animals are extremely complex. Discovering 
that an animal is intelligent is much less likely to produce expressions of human concern than discovering that it can suffer (Kasperbauer 2017:68).

Even though there is psychological evidence that people are less willing to eat animals that they consider human-like in terms of intelligence, there is also evidence that people will just ignore or willingly disbelieve information about animals' intelligence when this is convenient (Bastian et al. 2012). In a similar vein, it has long been widely known that rats are very smart, but strongly negative attitudes and extremely poor treatment of rats still prevail, especially when they are conceptualized as "pests".

In normative terms, there are few ethical positions according to which finding out that sheep are more intelligent than expected is very important for their moral status. What matters ethically is not intelligence but whether things can go well or badly for a sheep, from the sheep's own perspective, especially in terms of whether it can suffer. As Bentham (1789) famously puts it, "The question is not: "Can they reason? Nor "Can they talk?" But: "Can they suffer?".

There do exist some views according to which certain kinds of cognitive abilities increase animals' moral significance. Varner (2012), for example, argues that having "autonoetic consciousness" (a sense of one's own past and future) adds to an animal's moral importance. But even if autonoetic consciousness could be attributed to sheep, this would not be particularly relevant here; M\&M's concern is with shifting the view of sheep as commodities, not with finetuning questions about what might be owed to beings with autonoetic consciousness.

This is not to say that the kind of knowledge brought together in M\&M's paper is unhelpful for considering how sheep are used. In legal regimes in which sheep welfare matters, or in situations where those who handle sheep are concerned about sheep experiences, scientific analyses of what sheep minds are like is important. This kind of analysis gives us a better idea of what makes for a good life for a sheep. For example, it tells us something about how sheep need to be housed: they need social contact with other sheep and are distressed by living in isolation.

To conclude: Learning more about sheep intelligence is unlikely to have major effects on human psychological attitudes towards sheep. Sentience is, on most accounts, the key to moral status. We already knew that sheep were sentient. Hence M\&M's review is unlikely to change our view of sheep's moral status significantly. Where sheep welfare is already an issue of concern, the material M\&M provide is nevertheless useful in helping us understand what sheep need for better welfare.

\section{References}

Bastian, B., Loughnan, S., Haslam, N., and Radke, H. R. M. 2012. Don't mind meat? The denial of mind to animals used for human consumption. Personality and Social Psychology Bulletin 38(2) 247-256.

Bentham, J. 1789. An introduction to the Principles of Morals and Legislation.

Kasperbauer, T. J. 2017. Subhuman. NY: Oxford University Press.

Marino, L., and Merskin, D. 2019. Intelligence, complexity, and individuality in sheep. Animal Sentience 25(1).

Varner, G. 2012. Personhood, Ethics, and Animal Cognition: Situating Animals in the Two-Level Utilitarianism of R.M. Hare. NY: Oxford University Press. 